\title{
The effects of surfactant on haemodynamics in hyaline membrane disease
}

Artificial surfactant was first used to treat infants with hyaline membrane disease (HMD) by Chu et al 30 years ago. ${ }^{1}$ Benefit was measured by an increase in respiratory compliance in 34 of $43(79 \%)$ occasions, but these effects were overshadowed by those of the pulmonary vasodilator, acetyl choline. In this group of acidotic and hypoxaemic babies, acetyl choline improved blood gas status and reduced total right-to-left shunting; surfactant did not. The authors concluded that "pulmonary ischaemia" was more important than surfactant deficiency in the pathogenesis of HMD. Most now believe that surfactant deficiency is the major aetiological factor, and latterly exogenous surfactant treatment has significantly improved the outlook of babies with severe HMD. ${ }^{2}$

In the modern intensive care setting surfactant instillation rapidly improves respiratory gas exchange-very different from 30 years ago. There may, however, be a price to pay for such rapid changes in respiratory function. Surfactant instillation is often associated with dramatic haemodynamic changes, although studies have shown contradictory effects. Cerebral blood flow increases ${ }^{34}$ and decreases, perhaps by up to $36 \%{ }^{5}$; such changes may be associated with an increased incidence of intraventricular haemorrhage and periventricular leucomalacia. ${ }^{6}$ Similarly, studies of pulmonary arterial pressure (PAP) and pulmonary blood flow have also shown contradictory effects. Two groups who observed a fall in PAP have claimed that a primary action of surfactant is to increase total pulmonary blood flow ${ }^{7}$; but another group reported no fall in PAP. ${ }^{9}$

The effect of surfactant on effective pulmonary blood flow (the proportion of blood perfusing ventilated alveoli) is also still uncertain. Chu et $a l^{1}$ and a recent study using Curosurf $^{10}$ demonstrated no effect on effective pulmonary blood flow despite a considerable improvement in oxygenation. Nevertheless, further recent research has prompted the conclusion that effective pulmonary blood flow does typically increase with surfactant. ${ }^{11}$ Debate about the mechanism of the early effects of surfactant therefore continues.

It is known that an increase in functional residual capacity coincides with better ventilation:perfusion characteristics, but the specific issue addressed here is the resultant haemodynamic effects. The crux is whether surfactant itself decreases pulmonary vascular resistance and thereby increases total pulmonary blood flow, as would be expected of a pulmonary vasodilator.

\section{Haemodynamics of hyaline membrane disease}

Two popular misconceptions lead to misinterpretation of haemodynamic data in HMD. The first is that HMD is still characterised by pulmonary hypoperfusion, and the second is that pulmonary arterial pressure reliably reflects pulmonary blood flow.

Doppler echocardiographic studies have shown that high PAP is a feature of HMD, but that it does not correlate with the severity of the disease, nor does it usually require treatment. ${ }^{12} 13$ Pure right-to-left ductal flow, which occurs when pulmonary arterial pressure is higher than systemic arterial pressure throughout the cardiac cycle (common in persistent fetal circulation or PFC) is extremely rare in HMD. ${ }^{12-14}$ When it does occur, it usually signifies that these infants have genuine pulmonary vasoconstriction which may respond to vasodilators. ${ }^{1516}$

Severe or fatal HMD is more commonly associated with generalised circulatory failure, biventricular dysfunction, and systemic hypotension than with increased pulmonary vascular resistance. ${ }^{12}{ }^{13}{ }^{17-19}$ Indeed, most infants have coexistent predominantly left-to-right ductal and atrial shunts. ${ }^{12-14}$ Systemic hypoperfusion is often exacerbated by ductal "steal," where aortic blood flow destined for the descending aorta is "stolen" into the pulmonary circulation through the arterial duct, particularly during diastole. ${ }^{20}$ This occurs because pulmonary vascular resistance is falling and is lower than systemic vascular resistance, and it results in high pulmonary blood flow. Just as animal studies of HMD have shown high pulmonary blood flow, ${ }^{21}$ a study of human infants with HMD showed that half had significantly increased pulmonary blood flow secondary to left-to-right ductal shunting, during the first 48 hours. ${ }^{22}$ This increase in pulmonary blood flow through the duct maintains a high PAP at the expense of a reduction in both systolic and diastolic aortic pressure. ${ }^{23}$

High rather than low total pulmonary blood flow is therefore a characteristic feature of HMD, and increasing total pulmonary blood flow further is unlikely to be helpful in most infants. These facts suggest that surfactant's beneficial effects are unlikely to be mediated through pulmonary vasodilation.

An important point to note from these studies is that pulmonary hypertension does not necessarily equate with low pulmonary blood flow. Indeed, arterial pressure is directly related to blood flow. Aortic pressure, for example, is used as a clinical parameter of systemic cardiac output; if aortic pressure rises, this does not mean that aortic blood flow has fallen. Pressure depends on both flow and resistance. Very high PAP can occur with high, normal, and low pulmonary blood flow such as, respectively, in an infant with a ventricular septal defect, a healthy term newborn, or one with PFC.

Measurements of PAP cannot be relied on to reflect pulmonary blood flow.

\section{Haemodynamic effects of surfactant}

THE ARTERIAL DUCT-SYSTEMIC AND PULMONARY ARTERIAL CIRCULATIONS IN BALANCE

It is important to remember that the systemic and pulmonary circulations are joined directly to each other via a large arterial duct during early HMD. ${ }^{12-14}$ The duct is always large when the first dose of surfactant is given in the first hours after birth and any change in one side of the circulation must have effects on the other. The balance of flow depends on vascular resistance on each side of the duct. For example, pulmonary vasodilation increases left-toright ductal steal, requiring an increased left ventricular 
output to maintain aortic flow beyond the duct. The left ventricle of a very low birthweight baby may be ill equipped to do this, particularly in the first hours of life, ${ }^{24}$ and systemic arterial perfusion may fall significantly.

The major influences on vascular tone are the arterial content of oxygen and carbon dioxide. Factors which cause pulmonary vasodilation (low $\mathrm{PaCO}_{2}$ and high $\left.\mathrm{PaO}_{2}\right)^{25}$ simultaneously cause systemic and cerebral vaso constriction. ${ }^{26}{ }^{27}$ It follows that if swings in systemic, and particularly cerebral blood flow, are to be avoided, large fluctuations in $\mathrm{PaO}_{2}$ and $\mathrm{PaCO}_{2}$ must also be avoided. It also follows that important clues about surfactant induced changes in the pulmonary circulation may come from the more numerous studies of systemic and cerebral haemodynamics.

\section{CEREBRAL CIRCULATION AND SURFACTANT}

Surfactant has no direct action in the brain, therefore cerebral vascular changes must be secondary either to its mode of administration or its actions within the lungs. A recent meta-analysis of surfactant trials concluded that risk of intraventricular haemorrhage was related to the management of surfactant delivery rather than the type of surfactant. ${ }^{6}$ One study showed a fall in cerebral blood flow velocity of $36 \%$ from two to 10 minutes after surfactant administration, with a fall in mean aortic pressure of $6 \mathrm{~mm}$ Hg. ${ }^{5} \mathrm{PaO}_{2}$ rose from $7.5 \mathrm{kPa}$ to $13.7 \mathrm{kPa}$ during this time when ventilatory pressure and $\mathrm{FIO}_{2}$ were not adjusted. When the $\mathrm{PaO}_{2}$ was normalised at 15 to 20 minutes, cerebral blood flow returned to its initial values. It seems likely that the rising $\mathrm{PaO}_{2}$ caused the fall in cerebral blood flow. In another large multicentre trial where ventilatory pressure was not altered during instillation, surfactant was associated with an increased risk of periventricular leucomalacia. ${ }^{28}$ Maintaining high inspiratory pressures like this during the phase of rapid improvement in pulmonary compliance may impede venous return to the heart by increasing intrathoracic pressure (as occurs with pneumothorax), thus reducing cardiac output and systemic arterial pressure.

Rises in cerebral blood flow after surfactant, on the other hand, occur only in babies with rising $\mathrm{CO}_{2} \cdot{ }^{29}$ Such rises (up to $38 \%$ increase in cerebral blood flow velocity when Exosurf was given rapidly over 5 minutes $^{3}$ ) may be avoided by giving surfactant more slowly, over 15 minutes. ${ }^{3}$

PULMONARY CIRCULATION AND SURFACTANT

Surfactant obviously does work within the lungs, but is it a pulmonary vasodilator? Unfortunately studies of PAP and flow ${ }^{7-9}{ }^{31}$ have largely failed to report either $\mathrm{PaO}_{2}$ or $\mathrm{PaCO}_{2}$ values before and after treatment. Furthermore, no study blinded an observer to clinical status. The results are therefore difficult to interpret; if surfactant is a pulmonary vasodilator, as is claimed, its haemodynamic effects must be shown to exceed those resulting from improved gas exchange alone.

\section{Pulmonary arterial pressure and surfactant}

Unlike Doppler signals of the cerebral circulation, echocardiographic signals have not been recorded continuously during administration. A recent case report of continuous monitoring of arterial blood pressure during surfactant administration, ${ }^{32}$ showed that similar mean blood pressure values from before and after treatment obscured a biphasic swing of $22 \mathrm{~mm} \mathrm{Hg}$ in a baby with a mean blood pressure of $33 \mathrm{~mm} \mathrm{Hg}$. Similar transient changes in the cardiopulmonary circulation during surfactant administration are likely, but they are as yet uninvestigated in newborn babies. The earliest available data are from 15 minutes after surfactant instillation, by which time blood gas status and other factors may have stabilised.

Doppler echocardiographic studies to date have produced apparently contradictory results. Two groups, one using right ventricular systolic time intervals-TPV/RVET (time to peak velocity at the pulmonary valve/right ventricular ejection time $)^{8}$ and the other using peak velocity of tricuspid regurgitation $(\mathrm{TR})^{7} 3031$ found a significant fall in pulmonary arterial pressure, coinciding with a fall in oxygen requirements after surfactant. However, another recent study using velocity of ductal flow to determine pulmonary arterial pressure reported no significant change. ${ }^{9}$ How much are these conflicting findings the result of differences in the techniques?

All of these three Doppler techniques have been incompletely evaluated against direct measurement in preterms because of ethical constraints; but each has advantages and disadvantages. ${ }^{33}$ However, the two groups which demonstrated a reduction in PAP within one hour of Exosurf administration used different methods $\left(\mathrm{TR}^{7}\right.$ and TPV/RVET ${ }^{8}$ ). Observer errors would have been similar before and after the surfactant, such that the grouped results presented probably reliably reflect mean change, regardless of the method used. Assuming subjective bias is negligible, it is probably safe to assume that PAP did fall in these studies.

Why, then, was an early fall in PAP not detected by Bloom et al using the third method (ductal flow velocities)? ${ }^{9}$ Several groups have found this method to be sensitive even to small changes in PAP, ${ }^{33}{ }^{34}$ so the method is not likely to be at fault. Differences may be due to the type or dose of surfactant used, ${ }^{35}$ but there were other important differences between the studies, making direct comparison between them difficult. For example, mean starting $\mathrm{FIO}_{2}$ in Seppanen et al's study was 0.437 , compared with 0.85 in that of Bloom et al. ${ }^{9}$ While Bloom et al found no early effect on PAP, re-analysis of their results suggests there may have been a more rapid fall than that normally seen during recovery from HMD. A comparison of the longitudinal data in children with HMD who did not receive surfactant, ${ }^{13}$ shows that the pulmonary to systemic arterial (Pa:Ao) pressure ratio fell more quickly in the study of Bloom et al (0.96:1 vs $0.86: 1$ at six hours to $0.66: 1$ vs $0.82: 1$ at 48 hours). Although we may conclude that PAP falls quicker on average after surfactant treatment than predicted, it remains uncertain whether the early changes are related to ventilation practices, blood gas status, or surfactant itself.

\section{Pulmonary blood flow and surfactant}

Reliable techniques to assess total pulmonary blood flow with Doppler echocardiography are not yet available in patients with a patent duct and foramen ovale. Doppler assessment of left ventricular output is a measure of pulmonary venous return, but this assumes minor interatrial shunting. Using this technique, there was no change after surfactant instillation in any of three separate studies. ${ }^{3736}$ Another method records flow velocity in the left pulmonary artery; some results have suggested increased pulmonary blood flow secondary to left-to-right ductal shunting after surfactant. A study using both methods, simultaneously reported an increase in left pulmonary artery velocity, but no change in left ventricular output. ${ }^{7}$ Again there is a paucity of data on blood gas values and these apparently paradoxical results suggests that one or other of the methods is misleading. Evidence to date, while far from conclusive, therefore favours no significant change in total pulmonary blood flow following surfactant, and this is further supported by study in animals. ${ }^{21}$ 


\section{Conclusions}

Pulmonary ischaemia with raised pulmonary vascular resistance is rare in HMD, despite increased PAP, and the beneficial effects of surfactant are therefore unlikely to be due to pulmonary vasodilation itself. Evidence to date suggests that the haemodynamic consequences of surfactant treatment are mostly due to how, rather than which, surfactant is given, and may be conveniently divided into three phases: immediate; early; and delayed:

Immediate effects (up to 10 minutes after instillation) are related to the mode of administration and are typically cerebral vasodilation with increased cerebral blood flow due to a rise in $\mathrm{PaCO}_{2}$, presumably a consequence of transient obstruction of the large airways with fluid. The pulmonary haemodynamic effects in this phase are not yet known, but a reduction in left-to-right ductal flow would be expected in association with a rise in $\mathrm{PaCO}_{2}$.

Early effects (roughly two to 20 minutes) are related to ventilatory management during rapid improvement in ventilation and blood gas parameters. These ventilatory improvements may occur faster with natural surfactants. While there may be an increase in effective pulmonary blood flow (a question still to be resolved), total pulmonary blood flow typically remains unchanged. However, failure to reduce ventilation causes hyperoxia and hypocarbia, reducing cerebral blood flow while simultaneously increasing pulmonary blood flow and left-to-right ductal flow. Systemic arterial flow and pressure are further reduced by maintaining high ventilatory pressure which can impede central venous return due to overexpansion of the lungs.

Delayed effects (12 to 48 hours) may be a more rapid resolution of pulmonary hypertension, presumably due to a more rapid resolution of the disease process.

Animal studies indicate that the possible benefit of rapid instillation of surfactant is better distribution within the lungs. ${ }^{37}$ In human neonates, instillation over 15 minutes seems to have no adverse respiratory effects compared with bolus instillation. ${ }^{3}$ In designing treatment protocols, therefore, it needs to be remembered that rapid instillation of surfactant causes potentially harmful swings in aortic and particularly cerebral blood flow. These may be minimised by giving surfactant slowly (over 15 minutes), carefully avoiding overventilation, and by minimising changes in arterial oxygenation.

Future studies should first concentrate on using Doppler echocardiographic assessments of arterial flow and pressure to evaluate haemodynamics during changes in blood gas status (independent of surfactant). ${ }^{38}$ Simultaneous evaluation of effective pulmonary blood flow using inert gas techniques would be of particular interest. Studies of surfactant treatment should include details of all relevant concurrent blood gas values, method of surfactant administration, and ventilatory management policy, and should at least differentiate subjects according to age and disease severity. Serial changes within individuals rather than grouped data may also give more insight into these complex physiological events.

I am grateful to Drs Rob Martin, Neil Marlow, Glynn Russell, Karen Gray and the anonymous reviewer for their helpful comments.

JON SKINNER

Department of Cardiology,

Bristol Royal Hospital for Sick Children,

St Michael's Hill,

Bristol BS2 8BF.

1 Chu J, Clements JA, Cotton EK, Klaus MH, Sweet AY, Tooley WH. Neonatal pulmonary ischaemia. Part 1: Clinical and physiological studies. Pediatrics 1967;40:709-82.

2 Morley CJ. Surfactant treatment for premature babies- a review of clinical trials. Arch Dis Child 1991;66:445-50.
3 Saliba E, Nashashibi M, Vaillant MC, Nasr C, Laugier J. Installation rate effects of Exosurf on cerebral and cardiovascular haemodynamics. Arch Dis effects of Exosurf on cere

4 Rabe H, Jorch G. Cerebral haemodynamics in perinatal pharmacology. Dev Pharmacol Ther 1991;17:128-32.

5 Cowan F, Whitelaw A, Wertheim D, Silverman M. Cerebral blood flow velocity changes after rapid administration of surfactant. Arch Dis Child 1992;66:1105-9.

6 Gunkel JH, Banks PL. Surfactant therapy and intracranial haemorrhage: review of the literature and results of new analysis. Pediatrics 1993; 92:77586.

7 Seppanen M, Kaapa P, Kero P. Acute effects of synthetic surfactant replacement on pulmonary blood flow in neonatal respiratory distress syndrome. Am $\mathcal{F}$ Perinatol 1994; 6:382-5

8 Hamden $\mathrm{AH}$, Shaw NJ. Changes in pulmonary arterial pressure in infants with respiratory distress syndrome following treatment with Exosurf. Arch Dis Child 1995;72:F176-9.

9 Bloom M-C, Roques-Gineste M, Fries F, Lelong-Tissier M-C. Pulmonary haemodynamics after surfactant replacement in severe neonatal respiratory distress syndrome. Arch Dis Child 1995;73:F95-8.

10 Alexander J, Milner AD. Lung volume and pulmonary blood flow measurements following exogenous surfactant. Eur f Pediatr 1995;154:392-7.

11 Milner AD. How does surfactant work? Arch Dis Child 1993;68:253-4.

12 Evans NJ, Archer LNJ. Doppler assessment of pulmonary artery pressure and extrapulmonary shunting in the acute phase of hyaline membrane disease. Arch Dis Child 1991;66:6-11.

13 Skinner JR, Boys RJ, Hunter S, Hey EN. Pulmonary and systemic arterial pressure in hyaline membrane disease. Arch Dis Child 1992;67:366-73.

14 Walther FJ, Benders MJ, Leighton JO. Persistent pulmonary hypertension in premature neonates with severe respiratory distress syndrome. Pediatrics 1992;90:899-904.

15 McIntosh N, Walters RO. Effect of tolazoline in severe hyaline membrane disease. Arch Dis Child 1979;54:105-10.

16 Roze JR, Storme L, Zupan V, Morville P, Dinh-Xuan, AT, Mercier JC. Echocardiographic investigation of inhaled nitric oxide in newborn babies with severe hypoxaemia. Lancet 1994;344:303-5.

17 Halliday H, Hirschfeld S, Riggs T, Liebman J, Fanaroff A, Bormuth C. Respiratory distress syndrome: Echocardiographic assessment of cardiovascular function and pulmonary vascular resistance. Pediatrics 1977;60:444-

18 Evans N, Kluckow M. Early determinants of right and left ventricular output in ventilated preterm infants. Arch Dis Child 1996;74:F88-F94.

19 Gill AB, Weindling AM. Echocardiographic assessment of cardiac function in shocked very low birth weight babies. Arch Dis Child 1993;68:17-21.

20 Hiraishi S, Horiguchi Y, Misawa H, Oguchi K, Kadoi N, Fujino N, et al. Noninvasive Doppler echocardiographic evaluation of shunt flow dynamics of the ductus arteriosus. Circulation 1987;75:1146-53.

21 Kinsella JP, Gerstmann DR, Gong AK, Taylor AF, deLemos RA. Ductal shunting and effective systemic blood flow following single dose surfactant treatment in the premature baboon with hyaline membrane disease. Biol Neonate 1991;60:283-91.

22 Mellander M, Larrson LE, Ekstrom-Jodal B, Sabel KG. Prediction of symptomatic patent ductus arteriosus in preterm infants using Doppler and tomatic patent ductus arteriosus in preterm infants using Doppl
m-mode echocardiography. Acta Paediatr Scand 1987; 76:553-9.

23 Evans N, Moorcroft J. Effect of patency of the ductus arteriosus on blood pressure in very preterm infants. Arch Dis Child 1992;67:1169-73.

24 Takahashi Y, Harada K, Ishida A, Tamura M, Takada G. Left ventricular preload reserve in preterm infants with patent ductus arteriosus. Arch Dis Child 1993;71:F118-21.

25 Peckham GJ, Fox WW. Physiologic factors affecting pulmonary artery pressure in infants with persistent pulmonary hypertension. $f$ Pediatr 1978;93:1005-10

26 Leahy FAN, Cates D, MacCallum M, Rigatto $\mathrm{H}$. Effect of $\mathrm{CO}_{2}$ and $100 \%$ $\mathrm{O}_{2}$ on cerebral blood flow in preterm infants. F Appl Physiol 1980;48:468$\mathrm{O}_{2}$ on

27 Lundstrom KE, Pryds O, Greisen G. Oxygen at birth and prolonged cerebral vasoconstriction in preterm infants. Arch Dis Child 1995;73:F81-

28 Horbar JD, Soll RF, Schachinger H, Kewitz G, Versmold HT, Lindner W, et al. A Eurpean multicentre randomised controlled trial of single dose surfactant therapy for idiopathic respiratory distress syndrome. Eur 7 Pediatr 1990;149:416-23.

29 Rabe H, Jorch G. Cerebral hemodynamics in perinatal pharmacology. Dev Pharmacol Ther 1991;17:128-32.

30 Kaapa P, Kero P, Saraste M. Synthetic surfactant replacement therapy decreases estimated pulmonary artery pressure in respiratory distress syndrome. Am f Dis Child 1992;146:961-4.

31 Kaapa P, Seppanen M, Kero P, Saraste M. Pulmonary heamodynamics after synthetic surfactant replacement in neonatal respiratory distress syndrome. F Pediatr 1993;123:1 15-9.

32 Halley GC, Stenson BJ, Laing IA, McIntosh M. Acute blood pressure response to surfactant administration. Arch Dis Child 1995;73:197.

33 Skinner JR, Boys RJ, Heads A, Hey EN, Hunter S. Estimation of pulmonary arterial pressure in the newborn: A study of the repeatability of four Doparterial pressure in the newborn: A study of the repeatability of four Dop-
pler echocardiographic techniques using repeatability indices and pler echocardiographic techniques using repe

34 Musewe NN, Poppe D, Smallhorn JF, Hellman J, Whyte H, Smith B, et al. Doppler echocardiographic measurement of pulmonary artery pressure from ductal Doppler velocities in the newborn. $f \mathrm{Am}$ Coll Cardiol 1990;15:446-56.

35 Speer CP, Gefeller O, Groneck P, Laufkotter E, Roll C, Hanssler L, et al. Randomised clinical trial of two treatment regimens of natural surfactant preparations in neonatal respiratroy distress syndrome. Arch Dis Child 1995;72:F8-13.

36 Halliday HL, McCord FB, McClure BG, McCreid M. Acute effects of surfactant in severe respiratory distress syndrome. Arch Dis Child 1989;64:1316.

37 Segerer H, van Gelder W, Engement FWM, van Woerkens LJPM, Cursteot $\mathrm{T}$, Obleden $\mathrm{M}$, et al. Pulmonary distribution and efficacy of exogenous surfactant in lung lavaged rabbits are influenced by the instillation technique. Pediatr Res 1993;34:490-4.

38 Bard H, Belanger S, Fouron JC. Comparison of effects of $95 \%$ and $90 \%$ oxygen saturations in respiratory distress syndrome. Arch Dis Child 1996; 75:F94-6. 